06

\title{
Температурная дисперсия диэлектрических характеристик композитов на основе полиэтилена и наноглин $\mathrm{Na}^{+}$ монтмориллонита
}

\author{
(C) С.Р. Иманова, ${ }^{1}$ Ш.М. Гасанли, ${ }^{2}$ У.М. Сафарзаде ${ }^{2}$ \\ ${ }^{1}$ Гянджинский государственный университет, \\ AZ-1143 Баку, Азербайджан \\ ${ }^{2}$ Институт ффизики НАН Азербайджана, \\ AZ-1143 Баку, Азербайджан \\ e-mail: Hasanli_Sh@rambler.ru \\ (Поступило в Редакцию 28 апреля 2018 г.)
}

Исследованы температурные дисперсии диэлектрических свойств композитов на основе полиэтилена и наноглин типа $\mathrm{Na}^{+}$монтмориллонита. Обнаружено, что в результате цикла нагрева-охлаждения диэлектрические характеристики образцов принимают новые значения, сохраняющиеся некоторое время. Предполагается, что данный эффект обусловлен термостимулированными процессами перераспределения зарядов на границе наполнитель-матрица и накопления их на более глубоких ловушках и, как следствие, возникновение неравновесных состояний среды.

DOI: 10.21883/JTF.2019.02.47076.168-18

\section{Введение}

В последние годы проводятся широкие исследования процессов получения композиционных материалов на основе полимеров и природных слоистых силикатов [110]. Этот класс новейших нанокомпозитов обладает синергизмом свойств исходных компонентов. Это связано с тем, что взаимодействие на межфазной границе приводит к изменению свойств отдельных компонентов системы, в результате чего композиционные материалы приобретают принципиально новые свойства по сравнению с составляющими их компонентами. Степень гетерогенности и соотношение между фазами часто являются основными для проявления эффекта синергизма. Именно сложность нанокомпозитов и обеспечивает их подчас уникальные свойства как материалов, предназначенных для использования в различных сферах науки и техники [6-9]. В частности, в области строительства (из-за высокой набухаемости наноглины) для увеличения механической прочности изделий, нефтяной промышленности, в медицине $[5,6]$ и т.д. Отметим, что в последние время интенсивно ведутся работы по получению новых нанокомпозиционных материалов на основе наноглин с оригинальными свойствами. Однако влияние наноглин на электрофизические свойства композитов за исключением некоторых работ $[5,11,12]$ остается малоизученным. Поэтому исследование диэлектрических свойств подобных материалов является актуальным для оценки возможности их применения при разработке реальных электронных устройств. Так, одним из важнейших параметров является их быстродействие, определяемое во многом скоростью релаксационных процессов. В связи с этим важно изучать механизмы поляризации и температурные зависимости поляризационных процессов в изучаемых материалах. В то же время температурные исследования релаксационных процессов в нанокомпозитах на переменном токе мало изучены. Поэтому продолжение изучения электропроводности и диэлектрических свойств, полимерных нанокомпозитных материалов на переменном токе в широком температурном диапазоне представляется нам актуальным.

Настоящая работа посвящена исследованию электрофизических свойств композитов на основе полиэтилена и наноглин типа $\mathrm{Na}^{+}$-MМТ (монтмориллонит) в режиме нагрев-охлаждение.

Отметим, что измерения диэлектрических параметров композитов в режиме нагрев-охлаждение позволяют исключить влияние абсорбированной влаги на параметры образцов.

\section{Методика эксперимента}

В качестве объектов исследования были взяты порошки полиэтилена (ПЭ) и $\mathrm{Na}^{+}$-ММТ (монтмориллонит)-бентонита (с толщиной частиц до $15 \mathrm{~nm}$ и длиной до $250 \mathrm{~nm}$ ) Дашсалахлинского месторождения Газахского района (Азербайджан). Отметим, что добываемые на этом месторождении бентонитовые глины содержат от 80 до 95\% монтмориллонита.

Исследуемые композиты были получены из гомогенной смеси порошков компонентов путем горячего прессования при температуре $485 \mathrm{~K}$ и давлении $15 \mathrm{MPa}$. Были исследованы композиты с составами 30\% $(\mathrm{MMT})+70 \%$ ПЭ и $50 \%(\mathrm{MMT})+50 \%$ П. Толщина образцов была равна $180 \mu \mathrm{m}$. С помощью импеданса E7-20 были измерены электрическая емкость $C$ и диэлектрические потери $D$ при частотах $20 \mathrm{kHz}$ и $1 \mathrm{MHz}$ в режиме нагрев-охлаждение. Образцы помещались 
в измерительную ячейку с прижимными контактами, которая, в свою очередь, помещалась в нагревательную систему. Процесс нагрев-охлаждение осуществлен в непрерывном режиме без изменения расположения измерительных электродов. Погрешности измерений не превышали 5\%. Все измерения проводились в открытой атмосфере. Используя измеренные значения емкости $C$ и диэлектрических потерь $D$ образцов, с помощью формул (1)-(4) были рассчитаны величины действительной $\varepsilon^{\prime}$, мнимой $\varepsilon^{\prime \prime}$ частей диэлектрической проницаемости и проводимости.

$$
\begin{gathered}
\varepsilon=\frac{c \cdot h}{\varepsilon_{0} \cdot s}, \\
\varepsilon^{\prime}=\frac{\varepsilon}{\sqrt{1+D^{2}}} \\
\varepsilon^{\prime \prime}=\varepsilon^{\prime} \cdot D, \\
\sigma=\varepsilon^{\prime} \varepsilon_{0} 2 \pi f D,
\end{gathered}
$$

где $h-$ толщина образца - м. $S$ - площадь контакта $\mathrm{M}^{2}$.

$$
\varepsilon_{0}=8,85 \cdot 10^{-12} \frac{F}{m} \text {. }
$$

Для изучения резистивного или диэлектрического состояния исследуемых композитов проводились оценки времени релаксации Максвелла:

$$
\tau_{M}=\rho \varepsilon \varepsilon_{0}
$$

где $\rho-$ удельное сопротивление образца $[\Omega \cdot \mathrm{m}]$. При воздействии на образцы переменным сигналом с частотой $\omega=2 \pi / T$, где $T-$ период колебаний, в предельных случаях при $T, \tau_{\mathrm{M}}-$ проявляются диэлектрические свойства, при $T^{\text {“ }} \tau_{\mathrm{M}}$ - проводниковые или резистивные свойства.

\section{Результаты и их обсуждение}

На рис. 1-4 представлены температурные зависимости реальной части диэлектрической проницаемости, диэлектрических потерь D и электропроводности нанокомпозитов на основе $30 \%$ (ММТ) $+70 \%$ ПЭ и 50\% $(\mathrm{MMT})+50 \%$ ПЭ в процессе нагрев-охлаждение (изза идентичности температурных зависимостей $\varepsilon^{\prime}, D$ и $\sigma$ в настоящей работе приводятся данные при $f=1 \mathrm{MHz}$ ). Характерной чертой этих зависимостей является то, что с ростом температуры нагрева с начала $\varepsilon^{\prime}, D$ и $\sigma$ растут, а с дальнейшим ростом температуры уменьшаются. При этом средняя величина относительной диэлектрической проницаемости, полученная для нанокомпозитов на основе $50 \%(\mathrm{MMT})+50 \%$ ПЭ при нагревании, составила $\varepsilon=15.4$, а при охлаждении $-\varepsilon=10.3$. Для композитов на основе $30 \%$ (ММТ) $+70 \%$ ПЭ были получены значения $\varepsilon=14.2$ и 12.7 соответственно. Напомним, что диэлектрическая проницаемость самой матрицы ПЭ составляет $\varepsilon=2,3$.

Относительное изменение диэлектрической проницаемости $\varepsilon^{\prime}, D$ и $\sigma$ с изменением температуры составило

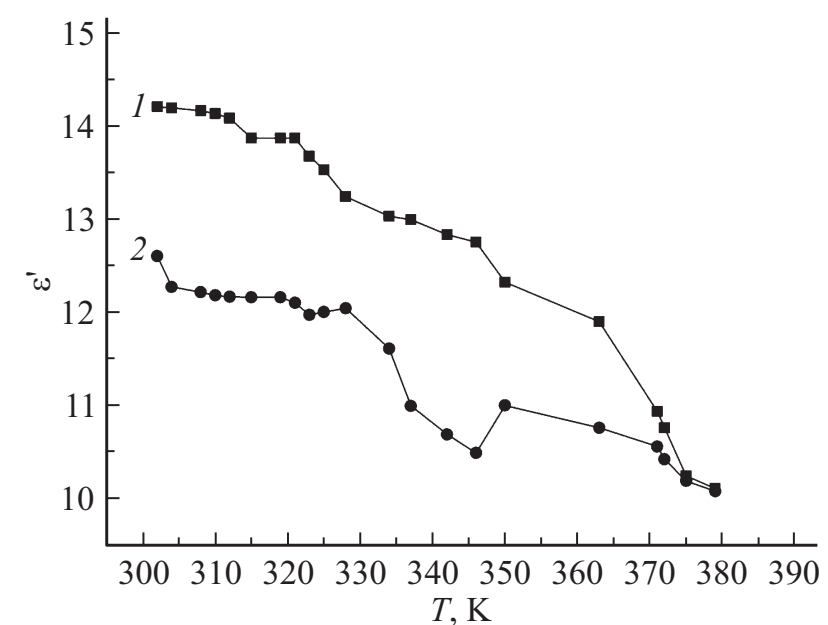

Рис. 1. Зависимость реальной части диэлектрической проницаемости от температуры при $f=1 \mathrm{MHz}$ для композита $30 \%$ MМТ + 70\% ПЭ. 1 - нагрев, 2 - охлаждение.

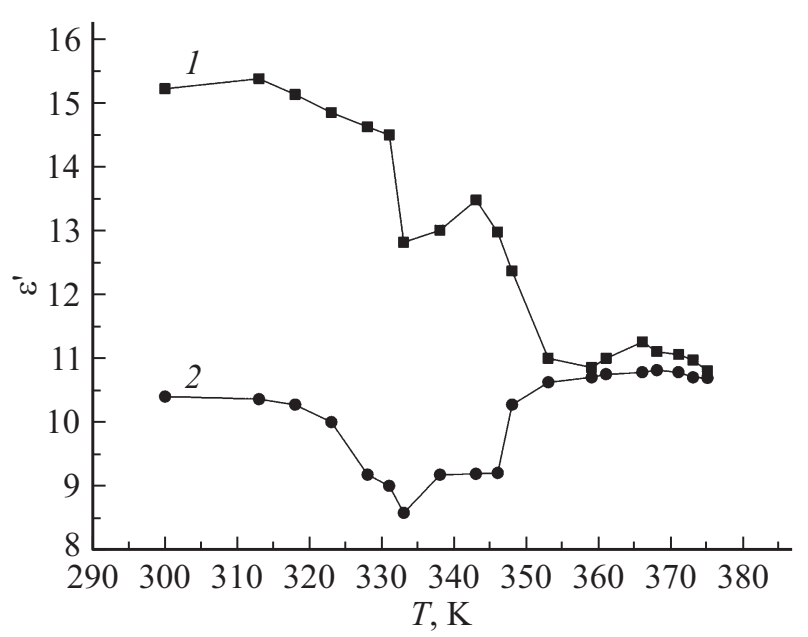

Рис. 2. Зависимость реальной части диэлектрической проницаемости от температуры при $f=1 \mathrm{MHz}$ для композита $50 \%$ $\mathrm{MMT}+50 \%$ ПЭ. 1 - нагрев, 2 - охлаждение.

примерно 33,11 и 60\% соответственно в ходе цикла нагрев-охлаждение.

Отметим, что в процессе нагрев-охлаждение наблюдается температурный гистерезис, который обусловлен большим динамическим диапазоном „размаха“"гистерезиса-разница величин электрофизических параметров в прямой (нагревание) и обратной (охлаждение) ветвях и особенно на начальных и конечных значениях температур. По-видимому, такое поведение можно объяснить наличием фазового перехода $(T>360 \mathrm{~K})$ полимерной матрицы.

Из рис.1-4 видно, что температурные зависимости $\varepsilon^{\prime}-, D$ - и $\sigma$-образцов в процессе охлаждения из высокотемпературной фазы до температуры $T=360 \mathrm{~K}$ практически полностью совпадают с кривыми нагрева, т.е. эффект гистерезиса проявляется при $T<360 \mathrm{~K}$, и 


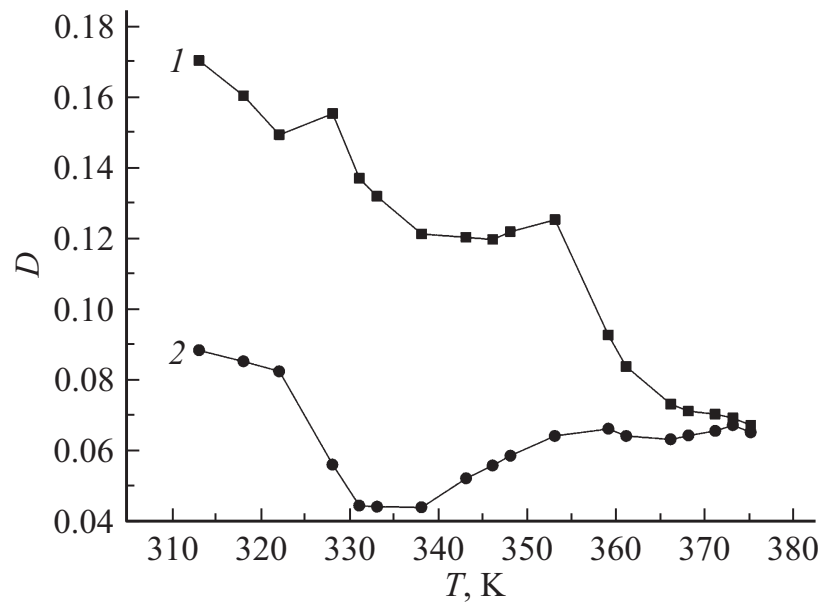

Рис. 3. Зависимость диэлектрических потерь от температуры при $f=1 \mathrm{MHz}$ для композита 50\% ММТ $+50 \%$ ПЭ. 1 нагрев, 2 - охлаждение.

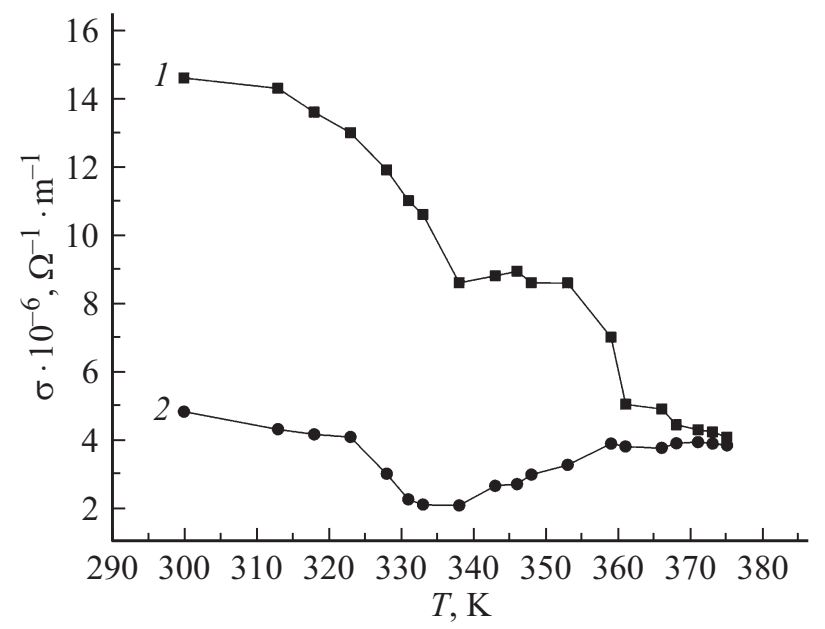

Рис. 4. Зависимость электропроводности от температуры при $f=1 \mathrm{MHz}$ для композита 50\% ММТ $+50 \%$ ПЭ. 1 - нагрев, 2 - охлаждение.

значение $\varepsilon^{\prime}, D$ и $\sigma$ для одних и тех же температур меньше при охлаждении, чем при нагревании образца. Начиная с $T=330 \mathrm{~K}$, значения $\varepsilon^{\prime}, D$ и $\sigma$ начинают расти, но не достигают первоначальных значений. В результате цикла нагрев-охлаждение диэлектрические характеристики образцов принимают новые значения, сохраняющиеся некоторое время (по меньшей мере в течение шесть дней). Такое поведение композита по мнению авторов работы [13] может быть связано с термостимулированным процессом перераспределения заряда на границе частица-матрица, его накоплением на более глубоких ловушках и, как следствие, возникновение неравновесных состояний среды. В таком состоянии образцы композита после охлаждения до комнатных температур могут находиться длительное время. Согласно работе [14], эта особенность композитов обусловливает гистерезисные явления, в основе которых лежит эффект, „асимметрии“ температурной эволюции электрически активных дефектов. Даже при небольших скоростях охлаждения макросистема не успевает достигать квазиравновесия (начальное состояние дефектов): исходные концентрации комплексов дефектов сразу не восстанавливаются, и возвращение образца в равновесное состояние требует длительной выдержки при комнатной температуре. Образование электрически активных дефектов в таких композитах при остывании может быть обусловлено и деформацией полимерной матрицы, возникновением механических напряжений на границе раздела наполнитель-полимер из-за различия в значениях коэффициента термического расширения и теплопроводности, а также электропроводности компонентов композита.

На рис. 5 представлена температурная зависимость времени максвелловской релаксации нанокомпозитов на основе $50 \%$ (ММТ) $+50 \%$ ПЭ $(1-$ нагрев, 2 - охлаждение). Оценки времени диэлектрической релаксаций Максвелла в образцах показали, что выполняется условие, когда время внешнего воздействия на среду много меньше времени Максвелла релаксации. В нашем случае время внешнего воздействия составило около $1 \mu \mathrm{s}$, в то же время самое малое время релаксации Максвелла около $10 \mu \mathrm{s}$. Таким образом, образцы композитных наноматериалов во внешнем электромагнитном поле ведут себя как диэлектрики.

Следует отметить одну особенность, полученных экспериментальных результатов, а именно скачкообразность температурных зависимостей исследуемых параметров. Согласно работе [15], размораживание молекулярной подвижности с ростом температуры имеет ступенчатый характер. С повышением температуры подвижность элементов структуры композитного наноматериала возрастает. Причем чем выше молекулярная подвижность, тем больше угол поворота диполей в электрическом поле. Поэтому характер электропроводности

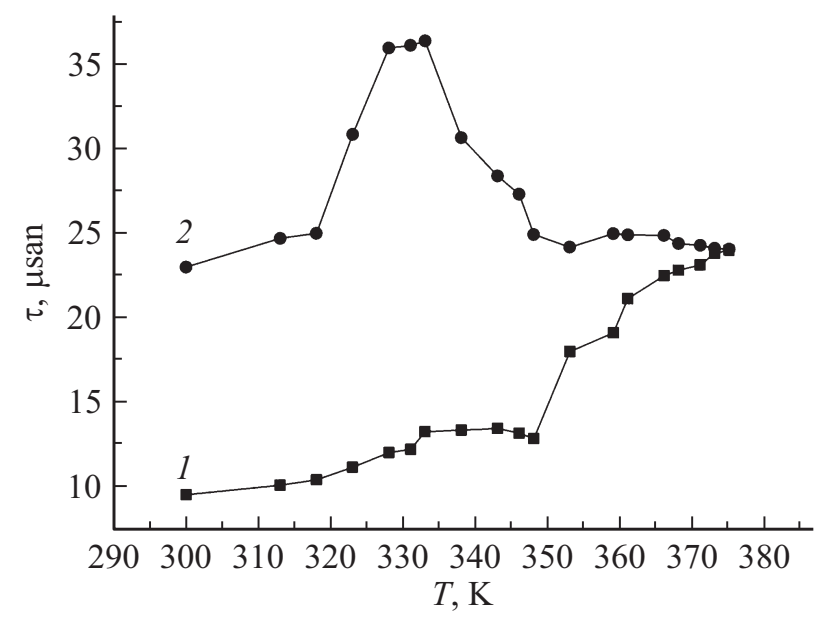

Рис. 5. Зависимость максвелловского времени релаксации от температуры при $f=1 \mathrm{MHz}$ для композита $30 \%$ ММТ $+70 \%$ ПЭ. 1 - нагрев, 2 - охлаждение. 
и связанных с этим зависимостей диэлектрической проницаемости и тангенса угла потерь могут иметь ступенчатый характер в некоторых областях температур. Такое поведение композитных наноматериалов указывает на тепловую природу некоторого „пускового“ механизма его молекулярной подвижности и связанных с этим особенностей в диэлектрических свойствах материалов.

Отметим, что общей закономерностью для измеренных зависимостей является рост энергии активации при нагреве и уменьшение ее при охлаждении, что соответствует изменению энергии носителей заряда с изменением температуры и, следовательно, изменению положения уровня Ферми внутри запрещенной зоны материала. Это может приводить к освобождению захваченных на ловушках зарядов с изменением диэлектрических свойств среды. Здесь также могут иметь место заметные скачкообразные переходы нанокомпозитной среды в новые энергетические состояния.

\section{Заключение}

Исследованы температурные дисперсии диэлектрических свойств композитов на основе полиэтилена и наноглин типа $\mathrm{Na}^{+}$монтмориллонита. Обнаружен температурный гистерезис зависимостей диэлектрических параметров композитов. Предполагается, что эффект обусловлен, „асимметрией“ температурной эволюции электрически активных дефектов. Другими словами, они сразу не восстанавливаются и возвращение образца в равновесное состояние требует длительной выдержки при комнатной температуре. Анализ результатов работы позволяет нам сделать вывод о том, что высоконаполненные композитные системы весьма чувствительны к температурным и частотным изменениям и могут представлять интерес для практического применения в различных областях науки и техники, например, в датчиках температуры и т.д.

\section{Список литературы}

[1] Damião Leitea A.M., Araujoa E.M.R., Anisioda Paza // Mater. Res. 2009. Vol. 12. N 2. P. $165-168$.

[2] Beyer G., Henrist C., Cloots R., Rulmont A., Jerome R., Duboi P. // Macromol. Rapid Commun. 2001. Vol. 22. N 8. P. $643-646$.

[3] Антипов Е.М. // ИФЖ. 2005. Т. 78. № 5. С. 35-48.

[4] Чвалун С.Н., Новокшокова Л.А., Коробко А.П., Бревнов П.Н. // РХЖ. 2008. Т. 3. № 5. С. 52-57.

[5] Першин Е.Д., Карпушин Н.А., Каздобин К.А. // Электронная обработка материалов. 2010. № 4. С. 60-67.

[6] Ястребинский Р.Н., Бондаренко Г.Г., Павленко В.И. // Перспективные материалы. 2015. № 6. С. 25-31.

[7] Мамедова Р.Л., Багирбеков Х.В., Аббасова Н.М., Гаджиева Е.Г. // Матер. рос. конф. Актуальность. Проблемы химии высоких энергий. М.: Изд-во Граница, 2015. C. $244-246$.
[8] Герасин В.А., Гусева М.А., Ребров А.В., Королев Ю.М., Антипова Э.М. // Высокомолек. соед. Сер. А. 2009. Т. 51. № 5. C. 454-468.

[9] Ушаков Н.М., Кособудский И.Д., Юрков Г.Ю., Губин С.П., Запсис К.В., Кочубей В.И., Ульзутуев А.Н. // Радиотехника. 2005. Т. 10. С. 105-109.

[10] He M.-C., Fang Z.-J., Zhang Ping // Chin. Phys. B. 2009. Vol. 18. C. 2933-2937.

[11] Магеррамов А.М., Мамедова Р.Л., Исмаилов И.М., Багирбеков Х.В. // ЖТФ. 2017. Т. 87. Вып. 9. С. 1367.

[12] Гасанли Ш.М., Иманова С.Р., Самедова У.Ф. // Электронная обработка. 2017. Т. 53. № 4. С. 81-89.

[13] Ушаков Н.М., Ульзутуев А.Н., Кособудский И.Д. // ЖТФ. 2008. Т. 78. Вып. 12. С. 65-69.

[14] Соцков В.А., Борисов В.А. // ЖТФ. 2007. Т. 77. Вып. 11. C. $103-108$.

[15] Лущейкин Г.А. Методы исследования электрических свойств полимеров. М.: Химия, 1988. 160 с. 